\title{
Michigan Arthroplasty Registry Collaborative Quality Initiative (MARCQI) as a model for regional registries in the United States
}

This article was published in the following Dove Press journal:

Orthopedic Research and Reviews

8 June 2015

Number of times this article has been viewed

\author{
Richard E Hughes ${ }^{1,2}$ \\ Brian R Hallstrom ${ }^{1,2}$ \\ Mark E Cowen ${ }^{1,3}$ \\ Rochelle M Igrisan ${ }^{1,2}$ \\ Bonita M Singal ${ }^{1,3}$ \\ David A Share 2,4 \\ 'Michigan Arthroplasty Registry \\ Collaborative Quality Initiative \\ (MARCQI), Ann Arbor, MI, USA; \\ ${ }^{2}$ Department of Orthopaedic Surgery, \\ University of Michigan, Ann Arbor, \\ MI, USA; ${ }^{3}$ Quality Institute, St Joseph \\ Mercy Hospital, Ann Arbor, MI, \\ USA; ${ }^{4}$ Blue Cross and Blue Shield of \\ Michigan, Detroit, MI, USA
}

Background: The United States has been a difficult environment in which to develop arthroplasty registries, largely because of the absence of a national health system. The purpose of this paper is to describe the development of a statewide registry-based quality improvement collaborative in Michigan.

Methods: The Michigan Arthroplasty Registry Collaborative Quality Initiative (MARCQI) was started in 2011 to improve the quality of care for total hip and knee replacement patients in Michigan. It is funded by Blue Cross and Blue Shield of Michigan/Blue Care Network as part of their Collaborative Quality Initiative (CQI) program. The CQI concept depends on capturing high-quality data (clinical status, process, and outcome), rigorously developing risk-adjustment models, and presenting risk-adjusted data to collaborative members at four face-to-face meetings a year.

Results: MARCQI has grown to include 44 hospitals and 377 orthopedic surgeons. The registry contains 54,848 cases (18,421 hips and 36,427 knees). Four collaborative-wide quality improvement activities have been initiated: 1) transfusion reduction, 2) deep vein thrombosis and pulmonary emboli prevention, 3) infection prevention, and 4) readmission prevention.

Conclusion: The CQI model developed by Blue Cross and Blue Shield of Michigan/Blue Care Network can be adapted to hip and knee arthroplasty, which demonstrates that private payers can play a role in the development and promotion of arthroplasty registries in the United States.

Keywords: registry, arthroplasty, hip, knee, quality, collaboration

\section{Introduction}

Arthroplasty registries have been shown to be powerful tools for hip and knee replacement quality improvement. ${ }^{1}$ Despite the development of successful institutional registries, ${ }^{2,3}$ the United States has been a difficult environment in which to develop regional and national registries. Two efforts to develop nationwide registries failed ${ }^{4}$ prior to the start of the American Joint Replacement Registry (AJRR) in 2009. Only one health network registry (Kaiser Permanente) ${ }^{5}$ has been operating for more than 10 years, and a community registry (HealthEast Joint Replacement Registry) ${ }^{6}$ has been in operation for over 20 years. Registry development has been hindered by financial, legal, and privacy factors. Private payers have been reluctant to support a large registry that will benefit their competitors, legal impediments include ambiguous federal regulation regarding consent requirements, and privacy issues include reluctance of individuals and institutions to share Social Security Numbers.

Despite these challenges, we have developed the Michigan Arthroplasty Registry Collaborative Quality Initiative (MARCQI), a statewide consortium of 44 hospitals
Correspondence: Richard E Hughes University of Michigan, 2003 BSRB, 109 Zina Pitcher Place,

Ann Arbor, MI 48I09-2200, USA

Tel +l 7344742459

Fax + I 7346470003

Email rehughes@umich.edu 
representing more than 377 surgeons, which includes active, structured inter-institutional collaboration for quality and process/outcome improvement. The purpose of this paper is to describe the origin, structure, and progress of MARCQI in light of the challenges described.

\section{MARCQI overview}

MARCQI has three goals: 1) improve patient safety and the quality of care for patients undergoing total hip arthroplasty (THA) and total knee arthroplasty (TKA) procedures in Michigan, 2) improve quality of total joint replacement procedures by rapidly identifying poorly performing new orthopedic technologies through the analysis of registry outcome data, and 3) demonstrate to patients and purchasers that MARCQI institutions are improving the value of arthroplasty services by utilizing available resources responsibly and efficiently.

MARCQI is part of the Collaborative Quality Initiative (CQI) program developed and funded by the Value Partnerships program of Blue Cross and Blue Shield of Michigan/Blue Care Network (BCBSM/BCN). Financial support from $\mathrm{BCBSM} / \mathrm{BCN}$ for the operation of the MARCQI coordinating and data management centers is $\$ 1.48$ million annually. BCBSM/BCN's first CQI, which was started in 1997, focused on percutaneous coronary interventions. In 2004, BCBSM/BCN expanded the program to 13 other areas. ${ }^{7-9}$ The CQI model includes rigorously validated collection of data on patient risk factors, processes of care, and outcomes. These data are entered into a registry. Risk-adjusted outcomes are shared at face-to-face quarterly meetings in a non-punitive, confidential framework for orchestrated quality improvement. The CQI model has been shown to reduce complications. The Michigan Bariatric Surgery Collaborative has reduced complications from $8.7 \%$ to $6.6 \%$. The Percutaneous Cardiology Intervention CQI reduced in-hospital death by a relative $27 \%{ }^{10}$

Quarterly meetings are a critical part of the CQI model because they provide a forum for disseminating hospitalspecific data, sharing best practices, and developing consortium-wide quality improvement. Each site designates an orthopedic surgeon as their MARCQI clinical champion to attend quarterly meetings and promote quality improvement activities within their institution. Sites also send their clinical data abstractors, and quality administrator to each quarterly meeting. A hospital information technology specialist from each hospital is required to attend one quarterly meeting a year to receive information on updates to the registry and requirements for file-based upload of administrative data.
The quarterly meeting, which is a half-day in length, has three components: 1) a device committee meeting, 2) general assembly, and 3) break-out sessions. The device committee reviews data on implant performance using methods similar to those developed by the Australian Orthopaedic Association National Joint Replacement Registry. The committee consists of orthopedic surgeons, biostatistician, quality improvement expert, and two biomedical engineers. The general assembly is the focus of the meeting where collaborative-wide and hospital-specific risk-adjusted adverse event data are presented. Ample time is provided for discussion. Presentations on national guidelines are presented sometimes. Panel discussions are also included to share best practices. Hospitals with especially low risks are asked beforehand to provide representatives to serve on the panels. Extensive panel and audience interaction occurs. Following the general assembly there are break-out sessions for the clinical data abstractors and clinical champions. The clinical champion session, which forms the medical advisory committee, serves to prioritize quality improvement initiatives and provide input to the executive committee. It is important to note that the overall management and direction are guided by participating physicians through the medical advisory committee.

MARCQI consists of the participating sites, a coordinating center, a database vendor (Ortech, London, ON, Canada), and a data management center. The coordinating center, housed at the University of Michigan, oversees data quality, data use agreements, training of data abstractors, collaborative-wide quality improvement initiatives, budgeting, contracting for information technology, organization of quarterly meetings of collaborative members, and interfacing with BCBSM/BCN. It employs a project manager, three full-time data auditors, and an administrative assistant. Ortech, which is the information technology vendor, is responsible for developing and maintaining the registry database according to industry and regulatory security standards. It produces "dashboard" reports for sites and physicians that are available via the web. The data management center, which receives raw data from Ortech, cleans and validates the data, computes metrics of data completeness, prepares quarterly reports, conducts analyses for presentation at the quarterly meetings, and develops riskadjustment models. Day-to-day leadership of the coordinating center and data management center is provided, respectively, by a project manager and the Director of the Quality Institute at St Joseph Mercy Hospital - Ann Arbor.

To be eligible to participate in MARCQI, a hospital must satisfy two fundamental criteria: 1) be located in Michigan, and 2) perform at least 200 elective total hip 
or knee procedures (combined) annually. Conditions of participation are clearly stated at the time of site recruitment, and they also include: identify all eligible patients presenting at the facility, contribute data to MARCQI database on a weekly basis, provide adequate computer resources, have an active quality improvement committee, identify an onsite clinical champion, identify an administrative lead, identify an information technology administrative lead, hire clinical data abstractor(s), collaborate with the coordinating center, and collaborate with other MARCQI sites.

Each participating site contributes data on $100 \%$ of total hip and knee replacement procedures performed. Thus, all physicians performing these procedures at MARCQI sites contribute data to the registry. Annual audits of each site are performed to ensure that all eligible cases are entered into the database. The operating room log is compared to the database to ensure that all eligible cases are abstracted. At the end of the 150-day period the data record is locked. Thus, it is possible to have incomplete data. However, the annual audits also address data completeness.

Data are owned by the collaborative rather than BCBSM/ $\mathrm{BCN}$. BCBSM/BCN has found through the development of its CQI program that it is important to have a firewall between itself and the database to assure the integrity of the data and maintain participants' confidentiality and the collaborative, statewide quality improvement process. The focus on measurement to improve rather than to judge facilitates open sharing of best practices. BCBSM/BCN does not request identifiable patient, physician, or hospital data from MARCQI; however, it does receive aggregate data on the performance of the consortium and the range of performance of participants in a de-identified format.

Governance of MARCQI is organized around co-directors, an executive board, and a medical advisory committee. The MARCQI executive board consists of the co-directors, project manager, director of the data management center, committee chairs (patient-reported outcome measures, device, and data abstractor), and five orthopedic surgeons from participating sites. There is a larger medical advisory committee that consists of all site clinical champions, co-directors, project manager, and the data management center director. The executive committee and medical advisory committee meet quarterly. Also supporting the collaborative are a data and publications committee, a device committee that guides the analysis of implant data, and a patient reported outcome survey committee to develop methods for collecting patient reported outcome surveys in clinical practices and a clinical data abstractor committee.
Conflict of interest and confidentiality are carefully managed. MARCQI requires annual disclosure by all physicians and other personnel having access to collaborative data.

\section{Data organization}

MARCQI collects level I, II, and III data (defined later) on qualifying procedures (Table 1). It plans to collect level IV data starting in 2015. Level I data consist of data elements that define the operative intervention, including implant model and manufacturer, and includes protected health information such as name and Social Security Number. Level II has elements relating to adverse events, additional demographic information, and comorbidities. Level III consists of patient-reported outcomes surveys. Table 2 lists the data elements. The process for selecting data elements began in 2009, with the philosophy to minimize the number of data elements as much as possible so that there would be sufficient time to properly identify and follow-up patients,

Table I ICD-9-CM codes used to define inclusion criteria for cases

\begin{tabular}{|c|c|c|}
\hline $\begin{array}{l}\text { Procedure } \\
\text { name } \\
\end{array}$ & $\begin{array}{l}\text { ICD-9-CM } \\
\text { code } \\
\end{array}$ & Description \\
\hline $\begin{array}{l}\text { Total knee } \\
\text { replacement }\end{array}$ & 81.54 & Total knee replacement \\
\hline \multirow[t]{6}{*}{$\begin{array}{l}\text { Revision knee } \\
\text { replacement }\end{array}$} & 81.55 & $\begin{array}{l}\text { Revision total knee replacement, not } \\
\text { otherwise specified }\end{array}$ \\
\hline & 00.80 & $\begin{array}{l}\text { Revision of knee replacement, total (all } \\
\text { components) }\end{array}$ \\
\hline & 00.81 & $\begin{array}{l}\text { Revision of knee replacement, tibial } \\
\text { component including tibial insert }\end{array}$ \\
\hline & 00.82 & $\begin{array}{l}\text { Revision of knee replacement, femoral } \\
\text { component }\end{array}$ \\
\hline & 00.83 & $\begin{array}{l}\text { Revision of knee replacement, patellar } \\
\text { component }\end{array}$ \\
\hline & 00.84 & $\begin{array}{l}\text { Revision of knee replacement, isolated } \\
\text { revision of tibial insert }\end{array}$ \\
\hline $\begin{array}{l}\text { Total hip } \\
\text { replacement }\end{array}$ & 81.51 & $\begin{array}{l}\text { Total hip replacement, the femoral head } \\
\text { is excised, osteophytes are removed, } \\
\text { and acetabulum is reamed out before } \\
\text { replacement is inserted in the femoral shaft. }\end{array}$ \\
\hline \multirow[t]{5}{*}{$\begin{array}{l}\text { Revision hip } \\
\text { replacement }\end{array}$} & 81.53 & $\begin{array}{l}\text { Revision of hip replacement, not otherwise } \\
\text { specified }\end{array}$ \\
\hline & 00.70 & $\begin{array}{l}\text { Revision of hip replacement, both } \\
\text { acetabular and femoral components }\end{array}$ \\
\hline & 00.71 & $\begin{array}{l}\text { Revision of hip replacement, acetabular } \\
\text { component }\end{array}$ \\
\hline & 00.72 & $\begin{array}{l}\text { Revision of hip replacement, femoral } \\
\text { component }\end{array}$ \\
\hline & 00.73 & $\begin{array}{l}\text { Revision of hip replacement, acetabular } \\
\text { liner and/or femoral head only }\end{array}$ \\
\hline Hip resurfacing & 00.85 & $\begin{array}{l}\text { Resurfacing hip, total, acetabulum and } \\
\text { femoral head }\end{array}$ \\
\hline
\end{tabular}

Abbreviation: ICD-9-CM, International Classification of Diseases, Ninth Revision, Clinical Modification. 
Table 2 Data elements

\begin{tabular}{|c|c|}
\hline Data element number & Data element name \\
\hline I & Hospital - MARCQI Registered No \\
\hline 2 & Hospital - Full Name \\
\hline 3 & Hospital - Short Name \\
\hline 4 & Hospital - Street Address \\
\hline 5 & Hospital - City \\
\hline 6 & Hospital - State \\
\hline 7 & Hospital - Zip \\
\hline 8 & Hospital - Phone number \\
\hline 9 & Hospital - National Provider Identifier \\
\hline \multirow[t]{2}{*}{10} & Hospital - Patient Social Security Number \\
\hline & Hash Preference \\
\hline \multirow[t]{2}{*}{11} & Hospital - Patient Social Security Number \\
\hline & Hash Preference Decision Date \\
\hline \multirow[t]{2}{*}{12} & Hospital - Pre/Postoperative PRO Email \\
\hline & Method Preference \\
\hline \multirow[t]{2}{*}{13} & Hospital - Pre/Postoperative PRO Email \\
\hline & Method Preference Decision Date \\
\hline 14 & Surgeon - Registered Surgeon ID \\
\hline 15 & Surgeon - First Name \\
\hline 16 & Surgeon - Last Name \\
\hline 17 & Surgeon - Middle Name/lnitial \\
\hline 18 & Surgeon - National Provider Identifier (NPI) \\
\hline 19 & Surgeon - Hospital Privileges \\
\hline 20 & First Name - Patient \\
\hline 21 & Last Name - Patient \\
\hline 22 & Middle Name/Initial - Patient \\
\hline 23 & Suffix - Patient \\
\hline 24 & Date of Birth - Patient \\
\hline 25 & Year of Birth - Patient \\
\hline 26 & Sex - Patient \\
\hline 27 & Home Street Address - Patient \\
\hline 28 & Home City - Patient \\
\hline 29 & Home State - Patient \\
\hline 30 & Home Zip Code - Patient \\
\hline 31 & Home Phone Number - Patient \\
\hline 32 & Cell Phone Number - Patient \\
\hline 33 & Email Address - Patient \\
\hline 34 & Email Address - Not Available - Patient \\
\hline 35 & Social Security Number Hashed - Patient \\
\hline 36 & Education Level - Patient \\
\hline 37 & Employment Status - Patient \\
\hline 38 & Ethnicity - Patient \\
\hline 39 & Race - Patient \\
\hline 40 & Marital Status - Patient \\
\hline 41 & Profession - Patient \\
\hline 42 & PRO Security Question - Patient \\
\hline 43 & Security Answer - Patient \\
\hline 44 & Smoking Status \\
\hline 45 & Smoking Years - Patient History \\
\hline 46 & Smoking Packs Per Day - Patient History \\
\hline \multirow[t]{2}{*}{47} & Bleeding Disorder or Contraindication to \\
\hline & Anticoagulation - Patient History \\
\hline 48 & Postoperative Events \\
\hline 49 & Question not answered \\
\hline 50 & Death \\
\hline 51 & Date of Death \\
\hline 52 & $\begin{array}{l}\text { Withdrawn from MARCQI (withdrawn } \\
\text { from the registry) }\end{array}$ \\
\hline
\end{tabular}

Table 2 (Continued)

\begin{tabular}{|c|c|}
\hline Data element number & Data element name \\
\hline 53 & Deep Venous Thrombosis (DVT) \\
\hline 54 & Pulmonary Embolism (PE) \\
\hline \multirow[t]{2}{*}{55} & Deep Venous Thrombosis or Pulmonary \\
\hline & Embolism \\
\hline 56 & DVT or PE During Index Hospitalization \\
\hline 57 & DVT or PE Postdischarge \\
\hline 58 & Urinary Tract Infection (UTI) \\
\hline 59 & Hematoma \\
\hline 60 & Date of Hematoma \\
\hline \multirow[t]{2}{*}{61} & Hematoma Requiring Irrigation and \\
\hline & Debridement \\
\hline 62 & Date of Hematoma \\
\hline 63 & Deep Infection \\
\hline 64 & Readmission \\
\hline 65 & Emergency Room Visit without Readmission \\
\hline 66 & Dislocation \\
\hline 67 & Fracture (related to the total joint) \\
\hline 68 & Hardware (mechanical) failure \\
\hline 69 & Other Return to OR \\
\hline 70 & No 90-Day Postoperative Events \\
\hline 7I & Postoperative Event Date \\
\hline 72 & Postoperative Event Relationship \\
\hline 73 & $\begin{array}{l}\text { Event - Action Taken - Related to Case, } \\
\text { within } 90 \text { days - Patient }\end{array}$ \\
\hline 74 & Planned Hospital \\
\hline 75 & Hospital Medical Record Number (MRN) \\
\hline 76 & Encounter Number \\
\hline 77 & Joint \\
\hline 78 & Side \\
\hline 79 & Planned Surgeon \\
\hline 80 & Planned Date of Surgery \\
\hline 81 & Actual Date of Surgery \\
\hline 82 & Time of Surgery \\
\hline 83 & Principal Procedure (ICD-9-CM) \\
\hline 84 & Principal Procedure (CPT) \\
\hline \multirow[t]{2}{*}{85} & Principal Procedure Performed \\
\hline & (Descriptive) \\
\hline 86 & Is Primary Procedure? \\
\hline 87 & Principal Diagnosis (ICD-9-CM) \\
\hline 88 & Principal Diagnosis POA \\
\hline 89 & Insurer Type \\
\hline 90 & Age at Date of Surgery - Patient \\
\hline 91 & PRO Method \\
\hline 92 & Preoperative Albumin \\
\hline 93 & Preoperative Albumin Date \\
\hline 94 & Preoperative Creatinine \\
\hline 95 & Preoperative Creatinine Date \\
\hline 96 & Preoperative Hemoglobin \\
\hline 97 & Preoperative Hemoglobin Date \\
\hline 98 & Preoperative Platelet Levels \\
\hline 99 & Preoperative Platelet Levels Date \\
\hline 100 & Preoperative INR \\
\hline 101 & Preoperative INR Date \\
\hline 102 & MRSA/MSSA Screening \\
\hline 103 & MRSA/MSSA Screening Date \\
\hline 104 & MRSA/MSSA Screening Result \\
\hline 105 & MRSA Decolonized? \\
\hline
\end{tabular}


Table 2 (Continued)

\begin{tabular}{|c|c|}
\hline Data element number & Data element name \\
\hline 106 & Preoperative Surgical Checklist \\
\hline 107 & Preoperative Anticoagulation Medications \\
\hline 108 & Preoperative Antimicrobial Medications \\
\hline 109 & Preoperative Antiplatelet Medications \\
\hline 110 & Preoperative Diabetic Treatment \\
\hline III & Preoperative Diabetic Treatment - Diet \\
\hline 112 & Preoperative Diabetic Treatment - Insulin \\
\hline 113 & Preoperative Diabetic Treatment - Oral \\
\hline 114 & Preoperative Diabetic Treatment - Both \\
\hline 115 & Preoperative Diabetic Treatment - Other \\
\hline 116 & Preoperative Diabetic Treatment - None \\
\hline 117 & Preoperative Diabetic Treatment - Unknown \\
\hline 118 & Preoperative Steroids \\
\hline 119 & Preoperative Narcotics \\
\hline 120 & Assistive Devices \\
\hline 121 & Height - Patient \\
\hline 122 & Weight - Patient \\
\hline 123 & BMI at Date of Surgery - Patient \\
\hline 124 & Admission Date \\
\hline 125 & Admission Type \\
\hline 126 & Discharge Date \\
\hline 127 & Discharge Disposition \\
\hline 128 & Length of Stay in Days \\
\hline 129 & Blood Transfusion During Stay \\
\hline 130 & Date of Blood Transfusion \\
\hline 131 & Number of Units of Red Blood Cells (RBCs) \\
\hline 132 & Date of Action Taken for Event \\
\hline \multirow[t]{2}{*}{133} & American Society of Anesthesiologists \\
\hline & (ASA) Classification \\
\hline 134 & Intraoperative Complication - Fracture \\
\hline 135 & Intraoperative Complication - Nerve Injury \\
\hline \multirow[t]{2}{*}{136} & Intraoperative Complication - Tendon/ \\
\hline & Ligament Injury \\
\hline \multirow[t]{2}{*}{137} & Intraoperative Complication - Vascular \\
\hline & Injury \\
\hline 138 & Intraoperative Complication - Other \\
\hline 139 & Intraoperative Complication - None \\
\hline 140 & Anesthesia - Spinal \\
\hline $14 \mid$ & Anesthesia - Epidural \\
\hline 142 & Anesthesia - General \\
\hline 143 & Anesthesia - Block \\
\hline 144 & Anesthesia - Local \\
\hline 145 & Anesthesia - Other \\
\hline 146 & Surgical Approach \\
\hline 147 & Social Security Number Declined - Patient \\
\hline 148 & Optional Techniques - ETO (hip only) \\
\hline 149 & Optional Techniques - Computer Assisted \\
\hline 150 & Optional Techniques - Robotic Surgery \\
\hline 151 & Optional Techniques - Custom Implants \\
\hline \multirow[t]{2}{*}{152} & Optional Techniques - Prefabricated Blocks \\
\hline & (Knees Only) \\
\hline 153 & Surgical Incision Open Time \\
\hline 154 & Time from Incision to Closure \\
\hline 155 & Device Manufacturer \\
\hline 156 & Device Catalog Number \\
\hline 157 & Device Lot Number \\
\hline 158 & Postoperative Hemoglobin \\
\hline
\end{tabular}

(Continued)
Table 2 (Continued)

\begin{tabular}{|c|c|}
\hline Data element number & Data element name \\
\hline 159 & HGB Post, Patient with Nadir HGB $<7$ \\
\hline \multirow[t]{2}{*}{160} & HGB Delta, postoperative minus \\
\hline & preoperative levels \\
\hline 161 & Postoperative Hemoglobin Date \\
\hline 162 & Postoperative INR \\
\hline 163 & Postoperative INR Date \\
\hline 164 & Previous DVT/PE - Patient History \\
\hline \multirow[t]{2}{*}{165} & Previous Anterior Cruciate Ligament (ACL) \\
\hline & Surgery on Surgical Knee \\
\hline \multirow[t]{2}{*}{166} & Previous Arthroscopy on the Surgical Joint \\
\hline & - Patient History \\
\hline \multirow[t]{2}{*}{167} & Previous Infection on the Surgical (knee/hip) \\
\hline & Joint - Patient History \\
\hline 168 & Email Address - Opt Out - Patient \\
\hline \multirow[t]{2}{*}{169} & Smoking, Pack Years (if Applicable) Patient \\
\hline & History \\
\hline 170 & Preoperative $\mathrm{HbA}_{\mathrm{Ic}}$ Level \\
\hline 171 & Preoperative $\mathrm{HbA}_{\mathrm{Ic}}$ Date \\
\hline 172 & Preoperative Diabetes Mellitus \\
\hline 173 & Intraoperative Tranexamic Acid \\
\hline 174 & VTE Prophylaxis Type \\
\hline 175 & VTE Prophylaxis Date of Initiation \\
\hline 176 & VTE Prophylaxis Stop Date \\
\hline 177 & VTE Prophylaxis Duration \\
\hline 178 & VTE Prophylaxis - Chronic Treatment \\
\hline 179 & VTE Diagnostic Testing Performed \\
\hline 180 & VTE Diagnostic Testing Date \\
\hline 181 & VTE Diagnostic Testing Positive Result \\
\hline 182 & Unable to Access Surgeon Notes \\
\hline 183 & Complete Data Flag \\
\hline 184 & PROMIS-IO (I0 questions) \\
\hline 185 & HOOS-PS (5 questions) \\
\hline 186 & KOOS-PS (7 questions) \\
\hline
\end{tabular}

Abbreviations: MARCQI, Michigan Arthroplasty Registry Collaborative Quality Initiative; ID, identification; PRO, patient reported outcome; HGB, hemoglobin; OR, operating room; ICD-9-CM, International Classification of Diseases, Ninth Revision, Clinical Modification; CPT, current procedural terminology; POA, present on admission; MRSA, methicillin-resistant Staphylococcus aureus; MSSA, methicillinsensitive Staphylococcus aureus; BMI, body mass index; INR, international normalized ratio; ETO, extended trochanteric osteotomy; HBA Ic, hemoglobin Al c;VTE, venous thromboembolism; PROMIS, Patient Reported Outcome Measurement Information System; HOOS-PS, Hip Osteoarthritis Outcome Score-Physical Function Short form; KOOS-PS, Knee Osteoarthritis Outcome Score-Physical Function Short form.

collect key data elements, identify relevant complications in a consistent fashion, risk-adjust based on comorbidities, and assess technical aspects of the procedure. Changes to data elements are allowed only once per year.

MARCQI is an all-payer registry that uses manual abstraction from the medical record, administrative data uploads, medical device file uploads, and access to a statewide database of billing records. Each site has at least one clinical data abstractor, trained by the coordinating center, who is responsible for submitting all site-generated data into the registry. $\mathrm{BCBSM} / \mathrm{BCN}$ funds $80 \%$ of the cost 
of each data abstractor, according to an assumption that each abstractor can abstract 700 cases per year. Hospitals performing more than 700 cases annually are eligible for multiple abstractors. Data abstractors perform the manual medical record review for their hospitals, enter the corresponding data elements into an online interface, and ensure their sites upload administrative and device data to the registry. Data abstractors utilize the medical records systems of their institutions. They extract select data elements and enter them in an online form for the Ortech database. There is a 90-day post-operative time window for almost all events (the exception being revision, which can be captured indefinitely into the future). An incomplete data record is flagged by the system, and each abstractor can see a list of incomplete records. The abstractor is given 60 days past the 90-day window to complete the record, which creates a 150-day delay in providing complete data to the database for analysis. Device data included consist of device manufacturer catalog number, and lot number. Sites are given flexibility in how these data are captured. Some upload files generated by their supply chain data; others scan bar codes on packaging.

When a new site joins MARCQI, coordinating center staff perform an initial introductory visit and then an initial audit. Feedback for improvement is provided during the audits. Annual site audits are conducted to assure consistency and accuracy of data element interpretation across participating sites and to validate completeness and accuracy of data entered. Data abstractors are also required to attend quarterly meetings, during which there is a special break-out session for them to discuss data issues. The coordinating center also conducts periodic in-services to update and clarify data specifications, and distributes updated specifications and other correspondence.

Institutions are incentivized to participate in MARCQI through a variety of mechanisms. The first is the value of the data itself, which are provided back to the hospitals to facilitate quality improvement and allows benchmarking with others across the state. The second benefit is financial support to offset the salary for the data abstractor, who is encouraged to work on local quality improvement projects. The third is recognition as a participant in quality improvement and maintenance of "Blue Distinction Center" of BCBS/BCN. Finally, the hospitals are incentivized through a pay-for-performance program rewarding participation, attendance at collaborative meetings, and quality improvement gains. MARCQI advocates strongly for consortium-wide improvement goals rather than mere site-level progress to maintain the benefits of the collaborative effort and avoid counterproductive activity between sites.

The Michigan Inpatient Database (MIDB), which is managed and operated by the Michigan Health and Hospital Association Service Corporation, is used to track subsequent hospitalizations of the total joint cohort at any of the participating sites (regardless of where the index surgery was performed) over an open-ended follow-up period. The MIDB contains encounter-level inpatient hospital discharge (all payer) data that include the hospital medical record number, principal diagnosis and procedure, secondary diagnoses and procedures, diagnostic related group, discharge disposition, and basic demographic information. Michigan Health and Hospital Association Service Corporation technical staff create a unique patient identifier within their database using protected health information identifiers supplied by its member hospitals, and are able to match records of the index and subsequent hospitalizations at the patient level across participating hospitals. An extract of the MIDB data is submitted to the information technology vendor on a quarterly basis, contingent on the conditions specified in the data use and business associate agreements. For example, subject level data may not be shared with any payer organization, nor can the MIDB data be used to contact individual patients. Ortech then uses the hospital medical record number and other available patient identifiers to link the MIDB records to the corresponding patient data submitted by the MARCQI data abstractors. A summary of the data flow model is provided in Figure 1.

Privacy issues are paramount in MARCQI operations, and compliance activities require a significant amount of staff effort. MARCQI adheres to Health Insurance Portability and Accountability Act and Health Information Technology for Economic and Clinical Health privacy rules. Business associate and data use agreements are required for all sites. Additional agreements are required for those sites that request MARCQI to share their data with the AJRR. Because MARCQI is a quality improvement initiative rather than a research enterprise, it operates under the "not regulated" status defined by federal statutes for human subject research (45 Code of Federal Regulations 46) as advised by the University of Michigan's Institutional Review Board.

\section{Progress}

MARCQI grew in planned stages from two hospitals in 2011 to 12 in 2012, 29 in 2013, and 44 in 2014 (there are a total of 115 hospitals in Michigan, of which 55 perform more than 200 hip and knee replacements annually). In 2015 the 


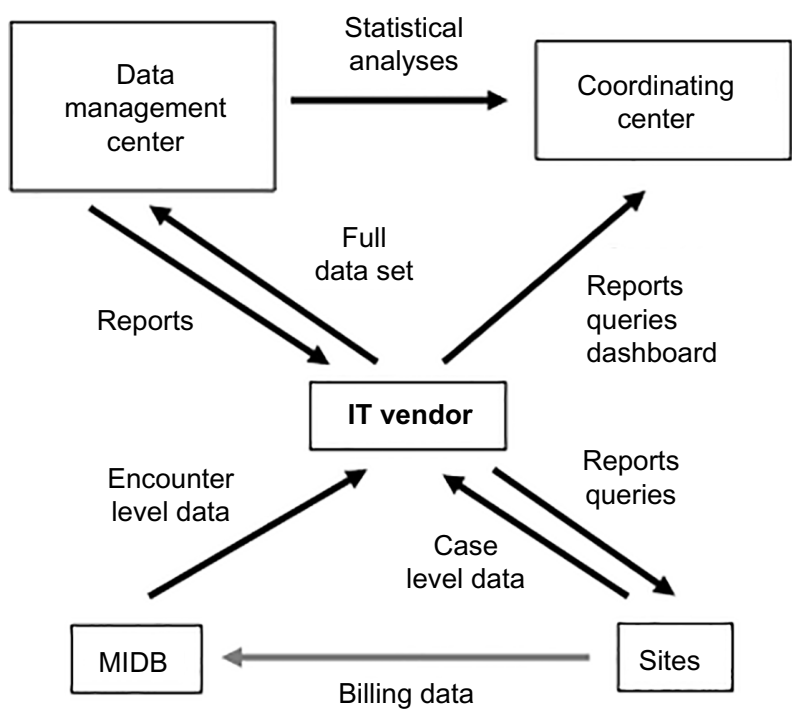

Figure I Data flow schematic illustrating elements of MARCQI and data flows between them.

Notes: Key activities include: I) participating sites submit case-level data along with protected health information (PHI) to the secure website of the information technology (IT) vendor (Ortech); 2) the Michigan Inpatient Data Base (MIDB) submits encounter-level data on elective total joint replacement surgeries performed at participating hospitals as well as the subsequent hospitalizations for these patients to the registry along with available $\mathrm{PHI}$ for linkage purposes only; 3) the IT vendor assigns a registry identification number for each unique patient as well as an identification number for each qualifying surgical event, and uses the available $\mathrm{PHI}$ to assign the applicable registry identification numbers to MIDB data; 4) the IT vendor provides the data management center with registry data (full data set) that has patient names, medical record numbers, and social security numbers removed; 5) the data management center prepares reports of aggregated data to the coordinating center and to the IT vendor that the sites access through the IT website; case-level data sets are also submitted to the IT vendor so that sites can access these and perform analyses of their own cases through an online query system; 6) the IT vendor provides reports, queries, and dashboard to the coordinating center. The link from sites to MIDB is represented in gray because this transfer of data is done outside of the MARCQI framework; all hospitals in Michigan submit their billing data for all inpatient discharges to MIDB independent of MARCQI.

Abbreviation: MARCQI, Michigan Arthroplasty Registry Collaborative Quality Initiative.

final cohort of hospitals will join to bring the total to 50 . The phased implementation contributed to systematic growth in database functionality, data definitions, staff growth, and development of operational policies and procedures. MARCQI hospitals range from community hospitals to large academic medical centers, and they are spread across the state (Figure 2). Growth in the number of registered cases has been rapid (Figure 3). As of October 27, 2014, a total of 54,848 cases had been registered $(18,421$ THA and 36,427 TKA). Full data collection lags because there is a 150-day window (90-days follow-up and 60 additional days allocated to complete data collection) for data to be fully abstracted. Thus, the number of cases that have completed the data abstraction period is 8,045 THA and 15,535 TKA. Eleven quarterly meetings have been held.

Completeness of level I and II data is $98.5 \%$. A case is defined as a scheduled qualifying procedure that matches

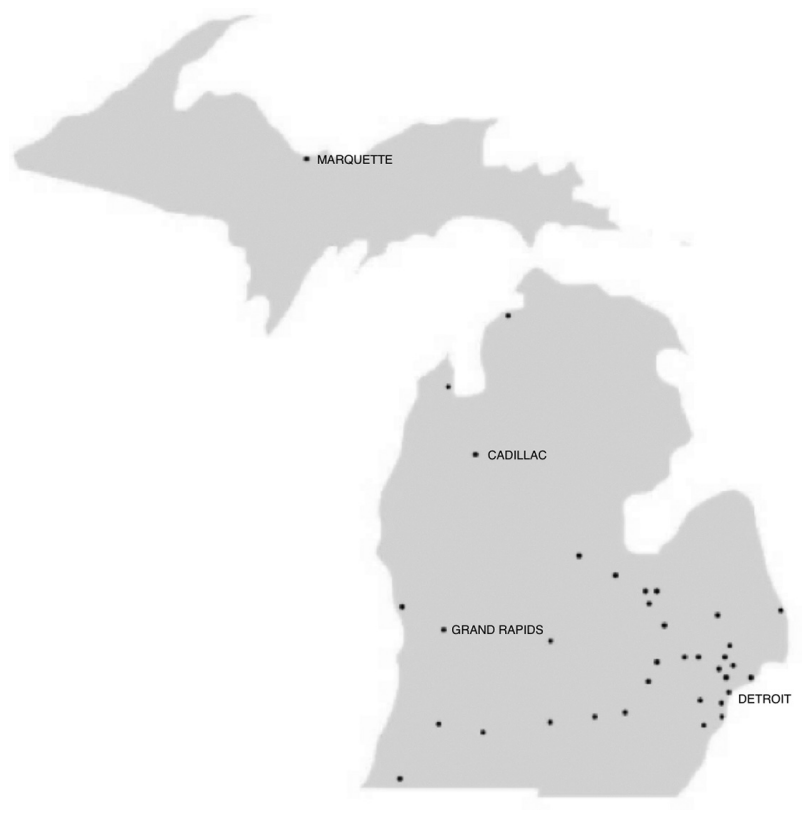

Figure 2 MARCQI sites across Michigan.

Notes: Dots indicate locations of participating hospitals. Both the lower and upper peninsulas of Michigan are represented.

Abbreviation: MARCQI, Michigan Arthroplasty Registry Collaborative Quality Initiative.

with an actual surgical procedure performed and contained in the hospital's operating room log. Eight key categories of data are required per case: 1) patient demographics, 2) laboratory values, 3 ) evidence that the surgery actually occurred (operating room file), 4) data about the operation itself, 5) information about the device implanted, 6) perioperative information, 7) information on whether or not venous thromboembolism prophylaxis was given, and 8) evidence

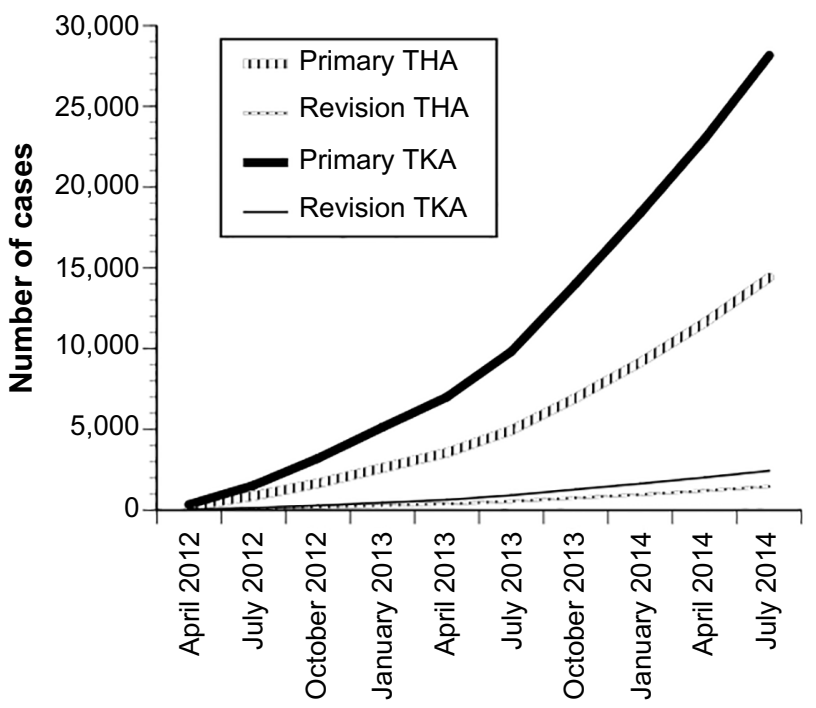

Figure 3 Growth of case registrations since inception (sum of primary and revision total hip and total knee arthroplasties).

Abbreviations: THA, total hip arthroplasty; TKA, total knee arthroplasty. 
Table 3 Collaborative-wide procedure and event statistics

\begin{tabular}{|c|c|c|c|c|c|c|}
\hline \multirow[t]{2}{*}{ Measure } & \multicolumn{2}{|c|}{ Unilateral TKA } & \multicolumn{2}{|c|}{ Bilateral TKA } & \multicolumn{2}{|l|}{ THA } \\
\hline & $\mathbf{N}$ & $\begin{array}{l}\text { Mean (SD) or } \\
\text { frequency (\%) }\end{array}$ & $\mathbf{N}$ & $\begin{array}{l}\text { Mean (SD) or } \\
\text { frequency (\%) }\end{array}$ & $\mathbf{N}$ & $\begin{array}{l}\text { Mean (SD) or } \\
\text { frequency (\%) }\end{array}$ \\
\hline Length of stay (days) & 15,532 & $2.6(1.2)$ & 447 & $3.6(1.6)$ & 8,042 & $2.6(1.4)$ \\
\hline Age (years) & 15,535 & $66.0(9.8)$ & 450 & $62.1(8.0)$ & 8,045 & $65.0(11.6)$ \\
\hline BMI $\left(\mathrm{kg} / \mathrm{m}^{2}\right)$ & 15,456 & $33.1(7.0)$ & 447 & $32.8(6.7)$ & 8,023 & $30.4(6.3)$ \\
\hline Sex & 15,504 & & 450 & & 8,035 & \\
\hline Female & & $9,593(61.9)$ & & $229(50.9)$ & & $4,352(54.2)$ \\
\hline Male & & $5,909(38.1)$ & & $221(49.1)$ & & $3,683(45.8)$ \\
\hline Race & & & & & 8,034 & \\
\hline Caucasian & 15,504 & 13,562 (87.5) & 450 & 418 (92.9) & & $7,066(88.0)$ \\
\hline Non-Caucasian & & $1942(12.5)$ & & $32(7.1)$ & & $968(12.0)$ \\
\hline Approach & 15,530 & & 896 & & 8,042 & \\
\hline Medial parapatellar, quad-splitting & & I2,668 (8I.6) & & $695(77.6)$ & & $\mathrm{N} / \mathrm{A}$ \\
\hline Lateral parapatellar & & $53(0.3)$ & & $5(0.6)$ & & $\mathrm{N} / \mathrm{A}$ \\
\hline Mid-vastus & & $2,237(\mid 4.4)$ & & $180(20.1)$ & & N/A \\
\hline Sub-vastus & & $438(2.8)$ & & $5(0.6)$ & & $\mathrm{N} / \mathrm{A}$ \\
\hline Posterior & & $\mathrm{N} / \mathrm{A}$ & & N/A & & $4,445(55.3)$ \\
\hline Anterior & & N/A & & $\mathrm{N} / \mathrm{A}$ & & $\mathrm{I}, 236(\mathrm{I} 5.4)$ \\
\hline Transtrochanteric & & $\mathrm{N} / \mathrm{A}$ & & N/A & & $76(0.9)$ \\
\hline Anterolateral & & $\mathrm{N} / \mathrm{A}$ & & N/A & & $2,232(27.8)$ \\
\hline Other/unknown & & $134(0.9)$ & & II (I.2) & & $53(0.6)$ \\
\hline Operative complications & 15,526 & & 896 & & 8,040 & \\
\hline Intraoperative fracture & & $33(0.2)$ & & $0(0.0)$ & & $109(1.4)$ \\
\hline Intraoperative nerve injury & & $2(0.0)^{c}$ & & $2(0.2)$ & & $5(0.1)$ \\
\hline Intraoperative tendon injury & & $13(0.1)$ & & $\mathrm{I}(0.1)$ & & $6(0.1)$ \\
\hline Intraoperative vascular injury & & $8(0.1)$ & & $0(0.0)$ & & $3(0.1)^{c}$ \\
\hline Other & & $20(0.1)$ & & $\mathrm{I}(0 . \mathrm{I})$ & & $16(0.2)$ \\
\hline 90-day events & 15,535 & & & & 8,045 & \\
\hline Dislocation ${ }^{\mathrm{a}}$ & & $6(0.0)^{c}$ & 900 & $0(0.0)$ & & $73(0.9)$ \\
\hline Deep infection ${ }^{\mathrm{a}}$ & & $56(0.4)$ & 900 & $3(0.3)$ & & $49(0.6)$ \\
\hline Fracture $^{a}$ & & $25(0.2)$ & 900 & $\mathrm{I}(0.1)$ & & $84(1.0)$ \\
\hline Hardware failure ${ }^{a}$ & & $3(0.0)^{c}$ & 900 & $0(0.0)$ & & $4(0.0)^{c}$ \\
\hline Other return to $\mathrm{OR}^{\mathrm{a}}$ & & $625(4.0)$ & 900 & $35(3.9)$ & & $45(0.6)$ \\
\hline Missing (not abstracted) ${ }^{\mathrm{a}}$ & & $150(1.0)$ & 900 & $16(1.8)$ & & $83(1.0)$ \\
\hline ED visit ${ }^{\mathrm{b}}$ & & I,449 (9.3) & 450 & $32(7.1)$ & & $659(8.2)$ \\
\hline Death $^{\mathrm{b}}$ & & $24(0.2)$ & 450 & $0(0.0)$ & & $17(0.2)$ \\
\hline Readmission ${ }^{\mathrm{b}}$ & & $833(5.4)$ & 450 & $14(3.1)$ & & $468(5.8)$ \\
\hline UTI & & $174(I . I)$ & 450 & $8(1.8)$ & & $108(1.3)$ \\
\hline
\end{tabular}

Notes: aComputed per procedure; bcomputed per hospitalization; ca small number of events occurred, but the percentage was less than $0.05 \%$ and is rounded to $0.0 \%$. Abbreviations: TKA, total knee arthroplasty; THA, total hip arthroplasty; SD, standard deviation; BMI, body mass index; N/A, not applicable; ED, emergency department; $\mathrm{OR}$, operating room; UTI, urinary tract infection.

that postoperative surveillance occurred and events recorded. MARCQI considers data submission "complete" if the site submits at least some data elements per key category per case. If no information is provided for any of the above eight categories of data, then the information is considered incomplete for the given case. Collection of level III data, however, lags far behind at only approximately $25 \%$. Overall collaborative performance is illustrated in Table 3.

Because there is variability in case mix between providers (hospitals or surgeons), it is necessary to adjust or standardize the risk estimates for patient-level variables that may contribute to an unwanted outcome. We do this using methodology developed by Yale New Haven for the Centers for Medicare and Medicaid Services. ${ }^{11}$ This entails fitting a logistic regression model to determine patient-level predictors for each outcome and then fitting these predictors in a hierarchical logistic regression model to estimate the risk of the outcome in patients cared for by that provider compared to what would be expected if the average provider cared for that same case mix. We initially calculated these metrics for all cases in the database, but as quality improvement initiatives have matured we are reporting the standardized ratios and risks as rolling estimates to capture changes in outcomes over time. 
MARCQI has initiated four collaborative-wide quality improvement projects: 1) red blood cell transfusion reduction, 2) deep venous thrombosis/pulmonary embolism prevention, 3) infection prevention, and 4) readmission prevention. Hospital-specific rates for each of these have been presented to the collaborative at quarterly meetings, with risk adjustment. The transfusion initiative focuses on reducing the percentage of cases in which a transfusion is given to patients with hemoglobin greater than $8 \mathrm{~g} / \mathrm{dL}$. It grew out of an initial investigation of bleeding rates and is in response to a growing body of literature that demonstrates increased risk of complications and mortality associated with use of transfusions during the same hospitalization. Data suggest a change in transfusion practices has occurred since initiation of this quality improvement project. The deep venous thrombosis/pulmonary embolism initiative has focused on highlighting the inter-site variability in prophylaxis regimens while MARCQI accrues a sufficient sample to compare the effectiveness of these practices. The infection prevention work includes achieving consensus on evidence-based prophylactic measures. The readmission project includes analysis of length of stay in the hospital as well as disposition at discharge (extended care facility, home care, home). This project is driven in part by the Center for Medicare and Medicaid Services Readmission Measure, which bases hospital reimbursement adjustments on readmission rates. MARCQI plans to better define the risk adjustment techniques and variables that influence readmission rates between patients and institutions and use that information to reduce readmissions and variability across institutions.

MARCQI encourages sites to participate in the AJRR. MARCQI uploads level I data to AJRR for hospitals that elect to have data submitted to AJRR. Twelve hospitals have chosen to do this.

\section{Limitations and future directions}

While MARCQI is an innovative approach to quality improvement and registries in the United States, it has limitations. Most notably, it is a regional effort contained within a single mid-sized state. Patient care events outside of Michigan following the primary procedure are not captured. However, MARCQI is able to capture events that require hospital admissions at other hospitals within Michigan other than the hospital where the arthroplasty procedure was performed. This is done through linking data with the MIDB, which contains the billing data for all hospital discharges in Michigan. The inability to capture revisions occurring outside of Michigan emphasizes the critical need for the development and success of the AJRR.

Future directions for MARCQI include medical device post-marketing surveillance and assisting others develop similar collaboratives. National registries such as the Swedish Hip Arthroplasty Register, Swedish Knee Arthroplasty Register, Australian Orthopaedic Association National Joint Replacement Registry, and the National Joint Registry of England, Wales and Northern Ireland have demonstrated the power of analyzing revision risk associated with individual implants and classes of implants. MARCQI seeks to conduct similar analyses in the future. Additionally, MARCQI leadership is interested in teaching others about the collaborative quality improvement model. Despite the limitations described earlier, there has been significant interest in the MARCQI model from others. MARCQI has received inquiries from hospitals, hospital systems, and payers in other states.

\section{Conclusion}

Michigan, similar in population size to Sweden, has developed a statewide hip and knee arthroplasty registry, which exists in the context of a structured, collaborative improvement consortium. Key functions include the collection of high-quality clinical data, rigorously developing riskadjustment models, and presenting risk-adjusted performance analysis to collaborative members at a face-to-face meeting four times a year. It has been shown to be effective by virtue of the high data capture rate within only a few years' time. This model had been refined by BCBSM/BCN and its physician/hospital partners during the development of other registries prior to the MARCQI launch. Consequently, the arthroplasty registry had the benefit of learning from others. An essential factor in the success of MARCQI has been the non-punitive nature of the endeavor in which the registry serves to inform and improve. While a payer is supporting MARCQI, it does not receive identified hospital, physician, or patient-level data. In fact, BCBSM/BCN supports MARCQI through a pay-for-performance incentive system for hospitals that emphasizes participation and improvement in collaborative-wide performance. Establishing the registry as a quality improvement activity also allows MARCQI to operate under federal regulations without requiring individual patient consent.

\section{Acknowledgments}

Funding for MARCQI CQI is provided by BCBSM and $\mathrm{BCN}$. The authors are grateful for the support of the participating sites' orthopedic surgeon champions and the effort 
of Tom Cichonski, April Richmond, Micki Speers, Mary Gumtow, Sherri McPhail, Steve Coon, Kelsey Blake, Jennifer Czerwinski, Jim Lee, Hal Morgenstern, and Kerri Kwapis.

\section{Disclosure}

REH, BRH, MEC, RMI, and BMS receive a portion of their salaries from MARCQI activity. DAS is an employee of BCBSM/BCN. BCBSM/BCN is not involved in MARCQI data collection and analysis and does not own the data or have access to it. BCBSM/BCN has not formally contributed to this manuscript as an institution or reviewed it prior to submission. However, DAS did contribute a BCBSM/BCN perspective on the CQI program and MARCQI. The authors have no other conflicts of interest to disclose.

\section{References}

1. Herberts P, Malchau H. Long-term registration has improved the quality of hip replacement: a review of the Swedish THR Register comparing 160,000 cases. Acta Orthop Scand. 2000;71(2):111-121.

2. Berry DJ, Kessler M, Morrey BF. Maintaining a hip registry for 25 years. Mayo Clinic experience. Clin Orthop Relat Res. 1997;(344):61-68.

3. Callanan MC, Jarrett B, Bragdon CR, et al. The John Charnley Award: risk factors for cup malpositioning: quality improvement through a joint registry at a tertiary hospital. Clin Orthop Relat Res. 2011;469(2): 319-329.
4. Saleh K, Goldberg M. Joint registries and the lessons learned from MODEMS. AAOS Bulletin. Rosemont, IL: American Academy of Orthopaedic Surgeons; 2004.

5. Paxton EW, Inacio M, Slipchenko T, Fithian DC. The Kaiser Permanente national total joint replacement registry. Perm J. 2008;12(3):12-16.

6. Gioe TJ, Killeen KK, Mehle S, Grimm K. Implementation and application of a community total joint registry: a twelve-year history. $J$ Bone Joint Surg Am. 2006;88(6):1399-1404.

7. Birkmeyer NJ, Birkmeyer JD. Strategies for improving surgical quality should payers reward excellence or effort? NEngl J Med. 2006;354(8): 864-870.

8. Birkmeyer NJ, Share D, Campbell DA Jr, Prager RL, Moscucci M, Birkmeyer JD. Partnering with payers to improve surgical quality: the Michigan plan. Surgery. 2005;138(5):815-820.

9. Share DA, Campbell DA, Birkmeyer N, et al. How a regional collaborative of hospitals and physicians in Michigan cut costs and improved the quality of care. Health Aff (Millwood). 2011;30(4):636-645.

10. Moscucci M, Rogers EK, Montoye C, et al. Association of a continuous quality improvement initiative with practice and outcome variations of contemporary percutaneous coronary interventions. Circulation. 2006;113(6):814-822.

11. Krumholz HM, Normand ST, Halusha DH, et al. Hospital 30-day acute myocardial infarction readmission measure. Available from: http://www.qualitynet.org/dcs/BlobServer?blobkey=id\&blobnocache= true $\&$ blobwhere $=1228873653724 \&$ blobheader $=$ multipart $\% 2$ Foctetstream\&blobheadername $1=$ Content-Disposition\&blobheadervalue $1=$ attachment\%3Bfilename\%3DAMI_ReadmMeasMethod.pdf\&blobcol= urldata\&blobtable $=$ MungoBlobs .
Orthopedic Research and Reviews

\section{Publish your work in this journal}

Orthopedic Research and Reviews is an international, peer-reviewed, open access journal focusing on the patho-physiology of the musculoskeletal system, trauma, surgery and other corrective interventions to restore mobility and function. Advances in new technologies, materials, techniques and pharmacological agents are particularly welcome. The journal welcomes

Submit your manuscript here: http://www.dovepress.com/orthopedic-research-and-reviews-journal

\section{Dovepress}

original research, clinical studies, reviews \& evaluations, expert opinion and commentary, case reports and extended reports. The manuscript management system is completely online and includes a very quick and fair peer-review system, which is all easy to use. Visit http://www.dovepress. com/testimonials.php to read real quotes from published authors. 